\title{
ANALISA SISTEM DISTRIBUSI 20 KV PADA SISTEM GRID PLTD BAKAU - GI KERANG
}

\author{
Ilham Febry Sudi Pratama ${ }^{1}$, Moethia Faridha ${ }^{2}$ \\ Program Studi Teknik Elektro, Fakultas Teknik, Universitas Islam Kalimantan ${ }^{12}$ \\ ilhamfebry11@gmail.com , bariethia@gmail.com
}

\begin{abstract}
Abstrak - Sistem yang digunakan PLTD Bakau yaitu sistem isolated yang masih menggunakan mesin diesel untuk mencukupi kebutuhan listrik di daerah Bakau. Namun dikarenakan semakin tahun semakin mahal Biaya Pokok Produksi (BPP) maka PT PLN (Persero) mulai memikirkan penghematan BPP dengan cara membangun Jaringan SUTM baru untuk di Interkoneksikan dengan GI terdekat dalam hal ini GI yang terdekat dari PLTD Bakau adalah GI Kerang, sehingga dilakukan pembangunan Jaringan SUTM baru untuk interkoneksi dengan GI Kerang. Pada saat pembangunan SUTM baru tersebut, perlu diperhatikan Losses daya dan tegangan ujung dihasilkan jika sudah interkoneksi dengan GI Kerang. Rugi - rugi daya atau Losses adalah energi yang terbuang selama perjalanan dari sumber menuju ke pelanggan. Semakin rendah nilai losses suatu jaringan maka jaringan tersebut dinyatakan handal dan bisa menyuplai pelanggan tanpa ada keluhan redup di pelanggan. Sehingga PLN selalu memperhatikan tegangan ujung yang ada sekarang, dan juga menjalankan program untuk menonaktifkan mesin diesel. Sehingga diharapkan suplai GI tersebut membuat tegangan menjadi lebih baik ketimbang suplai dari mesin diesel.Penelitian ini bertujuan untuk menganalisa sistem distribusi $20 \mathrm{kv}$ pada sistem grid PLTD Bakau - GI Kerang analisa sistem distribusi $20 \mathrm{Kv}$ dengan simulasi ETAP 12.6. Metode penelitian ini adalah metode untuk menganalisa losses yang dihasilkan.Dengan
\end{abstract}

cara Analisis Simulasi ETAP 12.6 dan Analisis Ekonomi untuk Grid PLTD Bakau - GI Kerang ada beberapa hasil yang didapat yaitu untuk analisis dengan ETAP 12.6 mendapatkan hasil losses tegangan menurun jika disupply dengan GI dan losses daya meningkat. Dan hasil losses daya mengalami peningkatan sebesar $157,4 \mathrm{Kw}$ dikarenakan beban Grogot dan Panjang jaringan grogot namun untuk losses tegangan mengalami penurunan sebesar 272,7 jika di supply dengan GI. Dari Analisis Ekonomi, mengalami keuntungan jika interkoneksi dengan Sistem Kaltim karena sudah tidak memakai mesin diesel lagi

Kata Kunci : Interkoneksi, Losses, ETAP 12.6

\section{I.PENDAHULUAN}

PT PLN (Persero) kini telah mencanangkan program Didieselisasi, yaitu program penonaktifan mesin mesin diesel untuk menghemat BPP PLN dan menaikkan rasio elektrifikasi dengan cara membangun Gardu Induk ataupun membangun jaringan SUTM baru yang nantinya akan interkoneksi dengan Gardu Induk terdekat. Dengan cara tersebut diharapkan tegangan ujung SUTM selalu mencapai standar dikisaran $19 \mathrm{Kv}$ dan rasio elektrifikasi meningkat.

Berdasarkan data Kemen SDM, rasio elektrifikasi Kalimantan Selatan mencapai 
$92,12 \%$. Dari data tersebut, berati masih ada masyarakat yang belum merasakan listrik di daerah pelosok seperti di daerah sawit,hutan,dan daerah lain yang belum terjamah oleh manusia. Sehingga diharapkan dengan adanya Grid PLTD Bakau - GI Kerang yang jalur SUTM nya melewati jalan setapak yang jarang dilewati oleh kendaraan umum dan menaikkan rasio elektrifikasi wilayah Kalimantan Selatan sesuai yang di targetkan oleh pemerintah sebesar 100.

Tujuan penelian ini adalah Mengetahui analisa sistem distribusi $20 \mathrm{Kv}$ dengan simulasi ETAP 12.6

\section{II.TINJAUAN PUSTAKA}

Sistem distribusi adalah sistem yang berfungsi mendistribusikan tenaga listrik kepada para pemanfaat. Sistem distribusi terbagi 2 yaitu: sistem distribusi tegangan menengah dan sistem distribusi tegangan rendah

Pengertian JTM, Menurut Standar Konstruksi Buku 5 yang berjudul "Jaringan Tegangan Menengah Tenaga Listrik " Pada pendistribusian tenaga listrik ke pengguna tenaga listrik disuatu kawasan, penggunaan sistem Tegangan Menengah sebagai jaringan utama adalah upaya utama menghindarkan rugi-rugi penyaluran (losses) dengan kwalitas persyaratan tegangan yang harus dipenuhi oleh PT PLN Persero selaku pemegang Kuasa Usaha Utama sebagaimana diatur dalam UU ketenagalistrikan No 30 tahun 2009.

Dengan ditetapkannya standar Tegangan Menengah sebagai tegangan operasi yang digunakan di Indonesia adalah $20 \mathrm{kV}$, konstruksi JTM wajib memenuhi kriteria enjinering keamanan ketenagalistrikan, termasuk didalamnya adalah jarak aman minimal antara Fase dengan lingkungan dan antara Fase dengan tanah, bila jaringan tersebut menggunakan Saluran Udara atau ketahanan Isolasi jika menggunakan Kabel Udara Pilin Tegangan Menengah atau Kabel Bawah Tanah Tegangan Menengah serta kemudahan dalam hal pengoperasian atau pemeliharaan Jaringan Dalam Keadaan Bertegangan (PDKB) pada jaringan utama.

Hal ini dimaksudkan sebagai usaha menjaga keandalan kontinyuitas pelayanan konsumen. Ukuran dimensi konstruksi selain untuk pemenuhan syarat pendistribusian daya, juga wajib memperhatikan syarat ketahanan isolasi penghantar untuk keamanan pada tegangan $20 \mathrm{kV}$.

Saluran Udara Tegangan Menengah (SUTM). Saluran Udara Tegangan Menengah (SUTM) adalah sebagai konstruksi termurah untuk penyaluran tenaga listrik pada daya yang sama. Konstruksi ini terbanyak digunakan untuk konsumen jaringan Tegangan Menengah yang digunakan di Indonesia. Ciri utama jaringan ini adalah penggunaan penghantar telanjang yang ditopang dengan isolator pada tiang besi/beton.

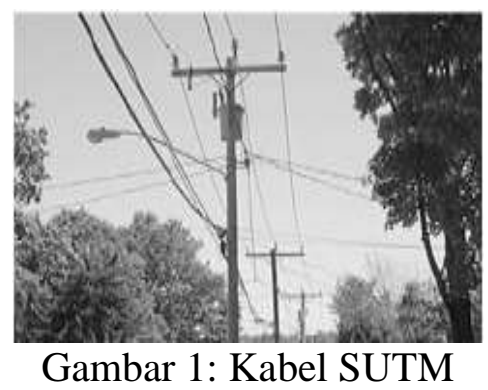

Pengertian Gardu. Menurut Buku Standar Konstruksi Buku 4 yang berjudul "Standar Konstruksi Gardu Distribusi dan Gardu Hubung Tenaga", Pengertian umum Gardu Distribusi tenaga listrik yang paling dikenal adalah suatu bangunan gardu listrik berisi atau terdiri dari instalasi Perlengkapan Hubung Bagi Tegangan Menengah (PHB-TM), Transformator Distribusi (TD) dan Perlengkapan Hubung Bagi Tegangan Rendah (PHB-TR) untuk 
memasok kebutuhan tenaga listrik bagi para pelanggan baik dengan Tegangan Menengah (TM $20 \mathrm{kV}$ ) maupun Tegangan Rendah (TR 220/380V

Tegangan Jatuh (Drop Tegangan). Menurut Standar Konstruksi Buku 1 yang berjudul "Kriteria Desain Engineering Konstruksi Jaringan Distribusi" Jatuh tegangan merupakan besarnya tegangan yang hilang pada suatu penghantar. Jatuh tegangan atau jatuh tegangan pada saluran tenaga listrik secara umum berbanding lurus dengan panjang saluran dan beban serta berbanding terbalik dengan luas penampang penghantar. Besarnya jatuh tegangan dinyatakan baik dalam \% atau dalam besaran Volt. Besarnya batas atas dan bawah ditentukan oleh kebijaksanaan perusahaan kelistrikan. Perhitungan jatuh tegangan praktis pada batas-batas tertentu dengan hanya menghitung besarnya tahanan masih dapat dipertimbangkan, namun pada sistem jaringan khususnya pada sisitem tegangan menengah masalah indukstansi dan kapasitansinya diperhitungkan karena nilainya cukup berarti.

\section{HASIL DAN PEMBAHASAN}

\section{Sistem Distribusi}

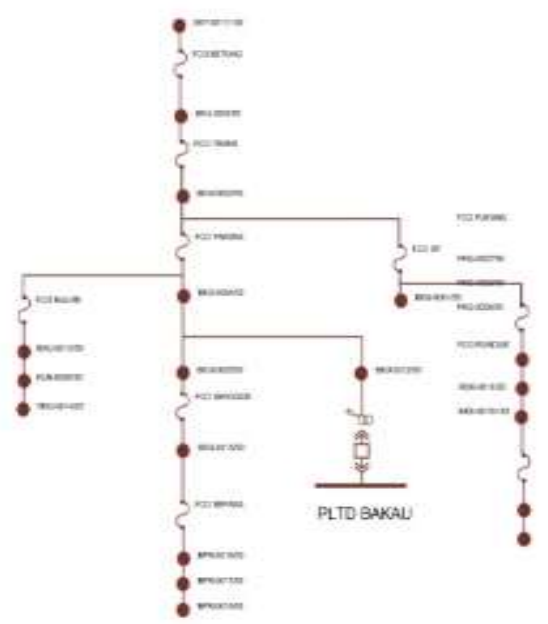

Gambar.2 Single Line Diagram PLTD Bakau

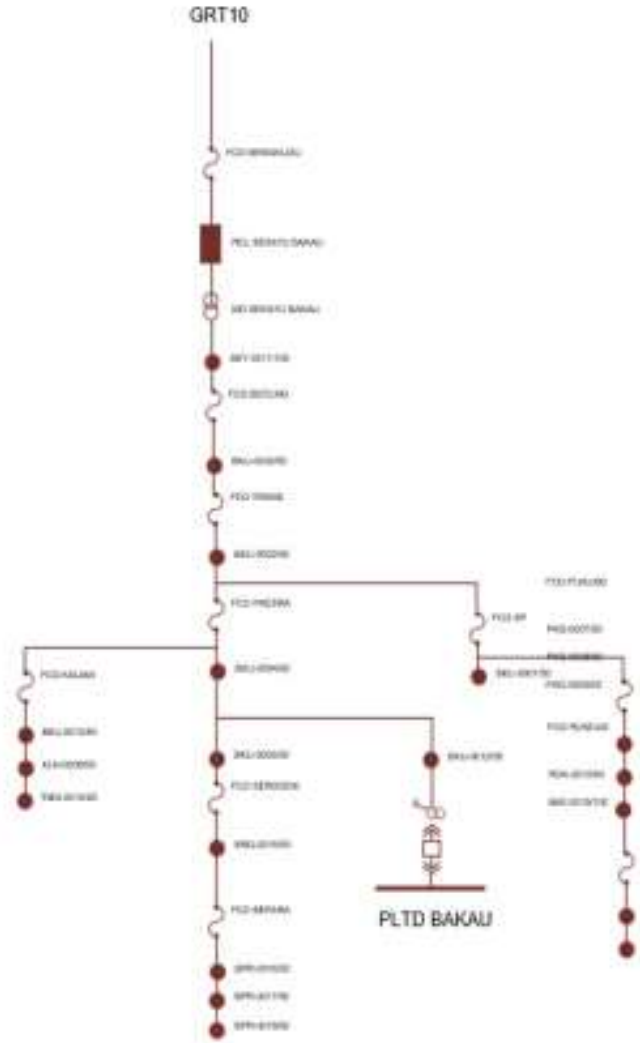

Gambar.3 Single Line Diagram Bakau Kerang

Faktor Investasi. Secara umum, sistem distribusi disini harus mempertimbangkan aspek investasi yang diharapkan memberikan keuntungan bagi perusahaan dikemudian hari. Dalam laporan ini akan membahas faktor investasi Grid PLTD Bakau-GI Kerang.

Tabel 1 Rekap PLTD Bakau Tahun 2019

\begin{tabular}{|c|c|c|c|c|c|}
\hline vo & Mesey & AxckTI & PAKAI (Rp) & BAR $Q R p$ & rot Al (Rp) \\
\hline 1 & 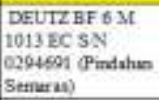 & $3,900,768$ & $75,202,458$ & & $79,103,226$ \\
\hline 2 & $\begin{array}{l}\text { DEUTZ F 6L. 912 } \\
\text { \$N } 8163 \text { F oss5 }\end{array}$ & 12.692 .500 & $240,558,524$ & & $262,251 \mathrm{A11}$ \\
\hline 3 & $\begin{array}{l}\text { DEUTZF 6L } 912 \\
\text { SN B163 D } 00003\end{array}$ & $8,131,254$ & $161,169,190$ & & $169,300,453$ \\
\hline 4 & $\begin{array}{l}\text { DELTZBF 4M } \\
1012 \text { ESN } \\
0011301\end{array}$ & - & - & & \\
\hline 3 & $\begin{array}{l}\text { DEUIZ BF GM } \\
10135 \mathrm{SC} \text { \&N } \\
11056630\end{array}$ & $59,560,024$ & $1,098,745,207$ & 101210.857 & $1,239,476,048$ \\
\hline 6 & 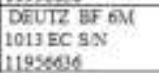 & $15,461,719$ & $1,59 \mathrm{~s}, 140,010$ & $101,230,857$ & $1,254,832,585$. \\
\hline 702 & & $135,656,654$ & $2,492,815,395$ & 262.461 .744 & $3,020,069,769$ \\
\hline
\end{tabular}


Biaya PLTD Bakau disini yang dimaksud disini terbagi menjadi 3 yaitu Biaya Pengangkutan BBM, Biaya Pemakaian BBM, dan Biaya Pemeliharaan Periodik. Untuk tahun 2019 saja, Biaya Pengangkutan BBM jenis Biosolar (B30) sebesar Rp. 135.686.654, Biaya Pemakaian BBM sebesar Rp. 2.682.815.395, dan Biaya Pemeliharaan Periodik sebesar Rp. 202.461.714. Sehingga didapat total pengeluaran PT PLN (Persero) untuk PLTD Bakau tahun 2019 sebesar Rp. 3.020.963.763. Nominal yang besar, mengingat semakin lama umur mesin, maka semakin besar juga kebutuhan BBM dan semakin besar lagi biaya yang akan dikeluarkan

Tabel.2 Biaya Pemakaian

\begin{tabular}{|c|l|c|}
\hline NO & \multicolumn{1}{|c|}{ MESIN } & \multicolumn{1}{|c|}{$\begin{array}{c}\text { JUMLAH } \\
\text { (Rp) }\end{array}$} \\
\hline 1 & $\begin{array}{l}\text { DEUTZ BF 6 M 1013 EC S/N 0294691 } \\
\text { (Pindahan Semaras) }\end{array}$ & $75,202,458$ \\
\hline 2 & DEUTZ F 6 L 912 S/N 8163 F 0685 & $249,558,521$ \\
\hline 3 & DEUTZ F 6 L 912 S/N 8163 D 0603 & $161,169,199$ \\
\hline 4 & DEUTZ BF 4 M 1012 E S/N 00134391 & \\
\hline 5 & DEUTZ BF 6M 1013 EC S/N 11956630 & $1,098,745,207$ \\
\hline 6 & DEUTZ BF 6M 1013 EC S/N 11956636 & $1,098,140,010$ \\
\hline & TOTAL & $2,682,815,395$ \\
\hline
\end{tabular}

Berdasarkan data diatas, maka untuk menghemat biaya tersebut dilakukan pembangunan jaringan SUTM baru untuk interkoneksi dengan Gardu Induk terdekat yaitu GI Kerang. Biaya yang diperlukan untuk membangun SUTM tersebut yaitu Rp. 3.698.642.928

Tabel 3 Perbandingan Biaya

\begin{tabular}{|c|c|c|c|}
\hline NO & BAKAU & $\begin{array}{c}\text { Tahun Pertama } \\
(\mathbf{R p})\end{array}$ & $\begin{array}{c}\text { Tahun Kedua } \\
(\mathbf{R p})\end{array}$ \\
\hline $\mathbf{1}$ & $\begin{array}{c}\text { VIA } \\
\text { PLTD }\end{array}$ & $3,020,963,763$ & $3,020,963,763$ \\
\hline $\mathbf{2}$ & VIA GI & $3,698,642,928$ & $1,606,441,224$ \\
\hline \multicolumn{2}{|c|}{ DELTA } & $(\mathbf{6 7 7 , 6 7 9 , 1 6 5 )}$ & $\mathbf{1 , 4 1 4 , 5 2 2 , 5 3 9}$ \\
\hline
\end{tabular}

Vol. 3 No.2 Tahun 2020
Berdasarkan tabel diatas, terdapat perbandingan total biaya yang dikeluarkan PT PLN (Persero), yaitu pada tahun pertama mengalami kerugian sebesar Rp. 677.679.165 dikarenakan baru saja melakukan pembangunan SUTM untuk interkoneksi dengan GI Kerang. Namun, untuk ditahun kedua PT PLN (Persero) cukup mengeluarkan biaya pemeliharaan jaringan agar selalu handal sebesar Rp. 1.606.441.224 sehingga mengalami keuntungan sebesar Rp. 1.414.522.539 dan biaya tersebut bisa digunakan untuk keperluan perusahaan yang lain.

Analisa Tegangan Dengan Simulasi Etap. Sebelum memulai simulasi ETAP, perlu diperhatikan juga beberapa parameter yang bisa mempengaruhi hasil akhir dari ETAP. Adapun parameter yang dimasukkan adalah sebagai berikut :

\section{Tabel 4 Parameter ETAP}

\begin{tabular}{|l|l|}
\hline TEGANGAN GI KERANG & $150 \mathrm{KV}$ \\
\hline TEGANGAN KIRIM GI KERANG & $21 \mathrm{KV}$ \\
\hline KAPASITAS TRAFO GI KERANG & $30 \mathrm{MVA}$ \\
\hline UKURAN PENAMPANG & AAAC 150 \\
\hline PANJANG JARINGAN & $10 \mathrm{KM}$ \\
\hline BEBAN GROGOT & $3 \mathrm{MW}$ \\
\hline PANJANG JARINGAN (GRID) & $5,5 \mathrm{KM}$ \\
\hline UKURAN PENAMPANG (GRID) & AAAC 150 \\
\hline BEBAN BAKAU & $240 \mathrm{KW}$ \\
\hline
\end{tabular}

Analisa tegangan supply dari mesin dan supply dari GI

Tabel 5 Tabel Tegangan Supply

\begin{tabular}{|l|r|}
\hline \multicolumn{2}{|c|}{ TEGANGAN SUPPLY } \\
\hline SUPPLY & TEGANGAN (KV) \\
\hline TRAFO STEP UP & 19.38 \\
\hline GI KERANG & 21 \\
\hline DELTA & 1.62 \\
\hline
\end{tabular}




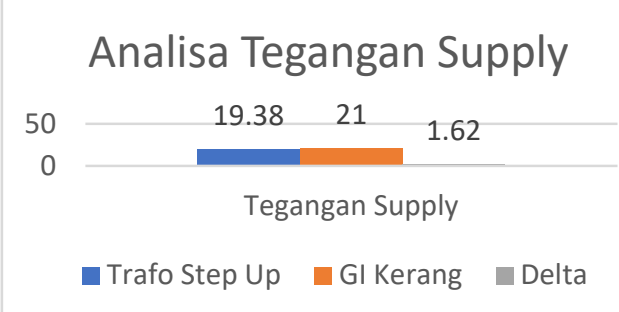

Gambar 4 Diagram Tegangan Supply

Berdasarkan data diatas, tegangan trafo step up dari mesin menghasilkan tegangan dengan nilai $19.38 \mathrm{Kv}$, sedangkan tegangan kirim dari GI Kerang sebesar 21 $\mathrm{Kv}$, sehingga terjadi kenaikan sebesar 1,62 Kv dari supply GI

\section{Tabel 6 Pengukuran Tegangan}

\begin{tabular}{|l|r|}
\hline \multicolumn{2}{|c|}{ GI KERANG } \\
\hline TEGANGAN KIRIM & 20.9 \\
\hline TEGANGAN SEKUNDER & 231 \\
\hline TEGANGAN UJUNG TM & 19.9 \\
\hline PARAMETER UKUR & 226 \\
\hline
\end{tabular}

Berdasarkan data pengukuran di atas, setelah penyesuaian Tap Trafo, Pengukuran serta menjaga tegangan kirim konstan di $20.9 \mathrm{Kv}$ didapatlah tegangan sekunder sebesar 231 Volt. Yang artinya, tegangan yang ada di pelanggan ujung bakau sebesar 226 volt sehingga pelanggan tidak ada mengalami gangguan redup dikarenakan tegangan drop

Analisa penurunan susut teknis. Faktor Susut. Dalam sistem distribusi, susut terbagi menjadi 2 yaitu susut teknis dan non teknis. Dalam masalah Grid PLTD Bakau - GI Kerang akan dibahas susut teknisnya. Berdasarkan table Losses, terdapat 2 lossess yaitu Losses Daya (Kw) dan Losses Tegangan (KVar).

Untuk losses Daya (Kw) melalui PLTD sebesar 113,4 sedangkan melalui GI sebesar 270,8. Sehingga terdapat perbedaan sebesar 157,4 Kw yang menandakan untuk susut teknis lebih tinggi melalui GI karena susut teknis semakin rendah semakin bagus.
Susut teknis GI lebih tinggi dikarenakan Beban Grogot sebesar 3 MW dengan Panjang Jaringan $10 \mathrm{Km}$.

Untuk losses Tegangan (KVar) melalui PLTD sebesar 404,0 sedangkan melalui GI sebesar 131,3. Sehingga terdapat perbedaan sebesar $-272,7$ KVar yang menandakan susut teknis lebih tinggi melalui PLTD. Adapun sebab penurunan lossestegangan karena Penyesuaian Tap Trafo serta menjaga tegangan konstan di nilai $20.9 \mathrm{Kv}$

Tabel 7: Losses

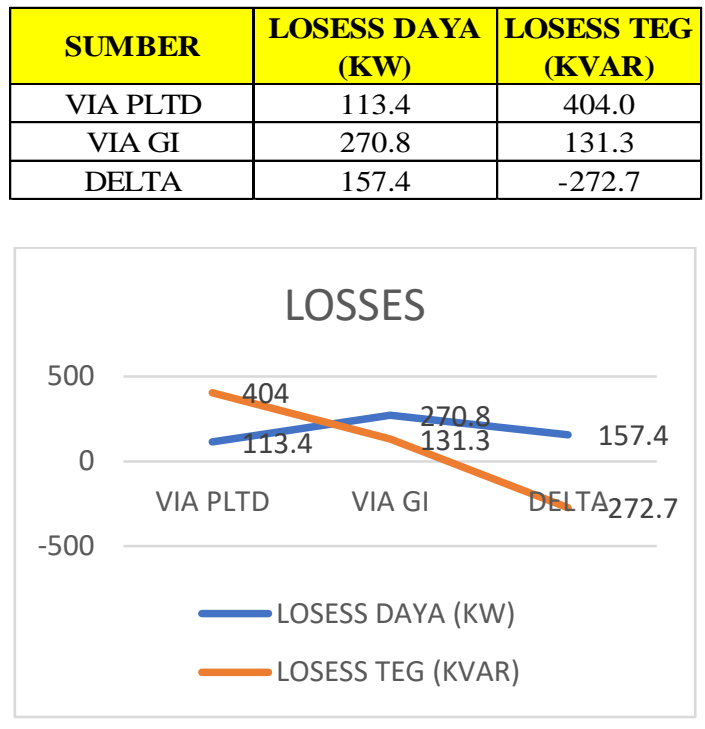

Gambar 5. Diagram Losses

Faktor Tegangan Ujung. Berdasarkan table 3.2 diatas, didapatkan nilai tegangan ujung antara PLTD Bakau dengan GI Kerang yaitu untuk PLTD Bakau 19,376 Kv dan GI 20,09 Kv. Sehingga ada penurunan sebesar $0,346 \mathrm{Kv}$ untuk tegangan menggunakan GI dan masih masuk standar tegangan ujung sesuai SPLN

Tabel 8: Tegangan Ujung.

\begin{tabular}{|c|c|}
\hline SUMBER & TEG $(\mathbf{K V})$ \\
\hline VIA PLTD & 19.376 \\
\hline VIA GI & 19.03 \\
\hline DELTA & 0.346 \\
\hline
\end{tabular}




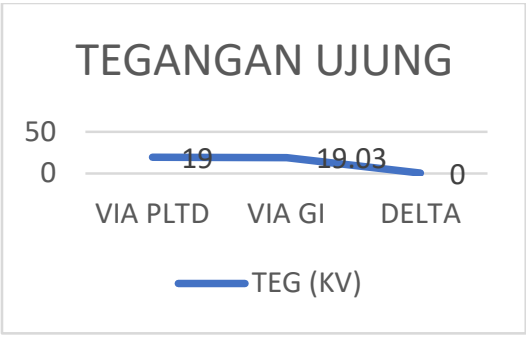

Gambar 6 Tegangan Ujung

Berdasarkan data analisa ETAP 12.6 dan analisa segi ekonomi, proses Grid PLTD Bakau - GI Kerang memiliki keuntungan dan kerugian. Adapun keuntungannya adalah bisa menghemat BPP dan Anggaran perusahaan ditahun kedua sebesar 1.414.522.539 sehingga bisa dialihkan untuk keperluan lain. Adapun kerugiannya adalah mengalami kenaikan losses daya sebesar 157,4 Kw dikarenakan beban Grogot dan Panjang jaringan grogot namun untuk losses tegangan mengalami penurunan sebesar 272,7 sehingga tegangan ujung pelanggan tidak redup.

\section{KESIMPULAN}

1. Melalui simulasi ETAP 12.6 disisi tegangan ujung, terjadi peningkatan jika di supply dari GI Kerang sebesar 1,62 $\mathrm{Kv}$ sehingga tegangan ujung di pelanggan tidak akan redup, Untuk losses tegangan, mengalami penurunan sebesar 272,7 Kv sehingga tegangan dinyatakan bagus supply melalui GI dengan catatan untuk tegangan selalu dimonitor di kisaran 20,9 Kv

2. losses daya, mengalami peningkatan sebesar 157,4 Kw dikarenakan sudah masuk Sistem Kaltim terutama jaringan Grogot sepanjang $10 \mathrm{Km}$ dan beban 3 MW sehingga losses menjadi besar

3. segi ekonomis dari pembangunan SUTM , mengalami kerugian sebesar Rp. 677.679.165 ditahun pertama. Namun ditahun kedua mengalami keuntungan sebesar Rp. 1.414.522.539 dikarenakan hanya menanggung biaya pemeliharaan sebesar Rp. 1.606.441.224

\section{DAFTAR PUSTAKA}

Anton Firmansyah. 2014. Modul Pelatihan ETAP. Palembang : Politeknik Negeri Surabaya

Kelompok Pembakuan Bidang Transmisi. 1987. Spesifikasi untuk Jaringan Tegangan Menengah (JTM) dan Jaringan Tegangan Rendah (JTR). Jakarta Selatan : PT PLN (Persero)

Kelompok Pembakuan Bidang Transmisi. 1995. Tegangan - Tegangan Standar. Jakarta Selatan : PT PLN (Persero)

Kurniawan, Arif. 2016. "Analisa Jatuh Tegangan Dan Penanganan Pada Jaringan Distribusi $20 \mathrm{Kv}$ Rayon Palur Pt. Pln (Persero) Menggunakan Etap 12.6". Surakarta : Universitar Muhammadiyah Surakarta

Noor, Fachry Azharuddin. 2017. "Pengaruh Penambahan Kapasitor Terhadap Tegangan, Arus, Faktor Daya, dan Daya Aktif pada Beban Listrik di Minimarket”. Jurnal Teknik Elektro Vol. 9 No. 2. Semarang: Universitas Negeri Semarang

Wibowo, Ratna dkk. 2010. Kriteria Desain Engineering Konstruksi Jaringan Distribusi Tenaga Listrik. Jakarta Selatan : PT PLN (Persero) 